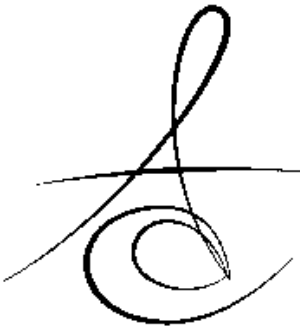

\title{
TAM PROTEZ KULLANMAYA BAŞLAYAN HASTALARIN HAYAT KALİTESİNİN VE ÇİĞNEME ETKİNLİĞİNİN İNCELENMESİ ${ }^{*}$
}

\section{ASSESMENTS OF LIFE QUALITY AND CHEWING EFFICIENCY OF PATIENTS USING NEW COMPLETE PROSTHESIS ${ }^{*}$}

\author{
Dr. Öğr. Üyesi Ayşe KOÇAK BÜYÜKDERE* $\quad$ Dr. Öğr. Üyesi Kübra DEĞİRMENCi்** \\ Dr. Bahar ODABAŞI ÖZGÜR ${ }^{* * *}$
}

Makale Kodu/Article code: 3188

Makale Gönderilme tarihi: 09.12.2016

Kabul Tarihi: 07.06.2017

\section{öz}

Amaç: Tam protezler ile kaybedilen çiğneme fonksiyonun kazanılması amaçlanır. Tam protezlere adaptasyon kişiden kişiye değişir ve hastaların yaşam kalitelerini etkilemektedir. Ağız sağlığı önemi profili [Oral Health Impact Profile (OHIP)], genel ağız sağlığı değerlendirme indeksi [General Oral Health Assessmnet Index (GOHAI)], ve günlük aktivitede ağız sağlığının önemi [Oral Impact on Daily Performance (OIDP)] anketleri yaşam kalitesini belirlemede sıklıkla kullanılmaktadırlar. Çiğneme etkinliği de tam protezlerin başarısında ve protezlere alışımasında önemli bir değerlendirmedir. Bu çalışmada hastaların tam protezlere alışma döneminde yaşam kalitesinin, çiğneme etkinliği ile beraber değerlendirilmesi amaçlanmıştır.

Gereç ve Yöntem: Bu pilot çalışma 2015 yılında Kocaeli Üniversitesi Diş Hekimliği Fakültesi Protetik Diş Tedavisi kliniğinde tam protez yaptıran 42 hasta üzerinde gerçekleştirildi. Yeni tam protez yapılan hastalara OHIP, GOHAI, OIDP anket soruları ilk gün, 24 saat, 1 hafta, 1 ay ve 3 ay sonraki kontrollerde sorulmuştur. Çiğneme etkinliğini belirlemek için de her seansta 20 ve 50 siklustan olmak üzere çift renk sakız çiğneme testi yapılmıştır. İstatiksel analiz bilgisayar destekli SPSS programında anketler Repeated Measure Anova ve Bonferroni testleri ile değerlendirilmiştir. Çiğneme testi için Ki-Kare testi kullanılmıştır.

Bulgular: OHIP, GOHAI, OIDP sonuçlarında ilk takıldıklarında, 1. günde, 1 . haftada, 1 . ay arasında anlamlı fark bulunmuştur. Birinci ay ve 3. ay arasında sadece OHIP'te anlamlı fark varken. GOHAI ve ODIP arasında anlamlı fark yoktur. Çiğneme etkinliği her seansta istatistiksel olarak artmıştır. Sadece ilk takıldığı an ve 1. gün arasında anlamlı fark yoktur.

Sonuç: Hastaların gelirleri ve eğitim durumları protez seçimini etkiler. Fiziksel olarak tam proteze adaptasyonları bir ay içinde çoğunlukla gerçekleşmektedir. Psikolojik adaptasyonu üç aya kadar sürmektedir. Çiğne- me etkinliği kullanımla beraber artmaktadır.

Anahtar Kelimeler: Tam protezler, ağız sağlığı, çiğneme

\section{ABSTRACT}

Aim: Complete dentures' aim is to gain the chewing function. Adaptation to complete dentures varies from person to person and also influence the patinent's life quality. The importance of oral health profile (OHIP), general oral health assessment index (GOHAI) and the importance of oral health in daily activities (OIDP) surveys are widely used to determine the quality of life. Chewing efficience is important assesment for prosthetic success and adaptation for the prosthesis. The aim of the study is to determine the relation between the quality of life and chewing effectiveness for the adaptation period with new complete dentures.

Material and Methods: This study was performed on 42 patients in Kocaeli Univercity Dental Faculty Prosthodontict Department in 2015 who are made new complete dentures. OHIP, GOHAI, OIDP surveys were asked to the new complete denture patients in first application, 24 hour, 1 week, 1 month, 3 months control. Chewing activity were measured by two colored gums in 20 and 50 siklus in the same control session.

Result: There are statistically meaningful differences were found between first insertion, 1 . day, 1 . week, 1 . month OHIP, GOHAI, OIDP surveys results. There is statistically difference between 1 . and 3. months in OHIP. But there are no statistically differences in GOHAI and OIDP. Chewing activity increased in every sessions. On the other hand there are no statistically differences between the inserting day and 1 . day.

Conclusion: Patient's income and education effect the prosthesis choices. Physical adaptation for complete dentures are nearly 1 month. Psychological adaptation takes nearly three months. Chewing activity is rising by using the dentures.

Keywords: Complete dentures, oral health, chewing

*Kocaeli Üniversitesi, Dişhekimliği Fakültesi, Protetik Diş Tedavisi AD, Kocaeli.

${ }^{* *}$ Abant İzzet Baysal Üniversitesi, Dişhekimliği Fakültesi, Protetik Diş Tedavisi AD, Bolu.

*** Emekli Dişhekim 
Atatürk Üniv. Diş Hek. Fak. Derg.

J Dent Fac Atatürk Uni

Cilt:28, Sayı:4, Yıl: 2018, Sayfa, 504- 510
KOÇAK BÜYÜKDERE,

DEĞİRMENCİ, ODABAŞI ÖZGÜR

\section{Gíriş}

Stomatognatik sistem; dişler, çeneler, dil, çiğneme kasları, ligamentler ve temporomandibular eklemden oluşur. Protetik diş tedavisinde amaç, dişlerle beraber kaybedilen çiğneme fonksiyonunu kabul edilebilir şekilde hastaya sağlamaktır. Bu amaçla, tam dişsiz hastalarda tam protez uygulamaları rutin tedavilerden biridir. ${ }^{1,2}$ Tüm dişlerini kaybetmiş hastalardan daha kuvvetli ve kontrollü çiğneme yapamama hissi prorio-septiv reseptörlerin olmamasından kaynaklanır. ${ }^{3-4}$

Yeni protezlerde çiğneme kaslarının hafızalarının şekillendiği ve alışma süreci açısından 6-8 haftalık periyodun önemli olduğu bildirilmektedir. ${ }^{5}$

Tam protezlerde yaşam kalitesi, anketlerle, protezlerin fonksiyonları çiğneme etkinliği testleri ile değerlendirilmektedir. Yaşam kalitesini belirlemede kullanılan anketler arasında ağız sağı̆ğı önemi profili [Oral Health Impact Profile (OHIP)], genel ağız sağlığı değerlendirme indeksi [General Oral Health Assessment Index (GOHAI)] ve günlük aktivitede ağız sağlığının önemi [Oral Impact on Daily Performance (OIDP)] anketleri bulunmaktadır. ${ }^{6-8}$ Çiğneme etkinliğini belirlemede ise elek yöntemi, yutma eşiği testi, bilgisayar destekli görüntü analizi, ezme yeteneği testi, renk ölçüm yöntemi, çift renkli sakız çiğneme testi, sakızdan salınan şeker miktarı testi en sık kullanılan testlerdir. ${ }^{1,9-12}$ Çift renkli sakız çiğneme testinde iki rengin karışımı değerlendirilerek veri elde edilmesi vakit kazandırdığı ve düşük maliyetli olması ile avantajlıdır. $^{12}$

Bu çalışmanın amacı, yeni tam protez yapılmış katılımcılara protezlere alışma dönemlerinde yöneltilen OHIP, GOHAI ve OIDP anket sorularından elde edilen veriler ile aynı seanslarda uygulanan sakız çiğneme testi verilerinin karşılaştırmalı olarak incelenmesi ve hastanın hayat kalitesi ile çiğneme etkinliği arasındaki ilişkiyi değerlendirmektir.

\section{GEREÇ VE YÖNTEM}

Kocaeli Üniversitesi Diş hekimliği Fakültesi Protetik Diş Tedavisi Anabilim Dalına tam protez yapılması için başvuran yaş ortalaması 61,54 olan (43-82) 26 kadın, 16 erkek olmak üzere toplam 42 hasta çalışmaya dahil edildi. Kocaeli Üniversitesi Tıp Fakültesi Etik Kurulu'nu izin alındı (KOÜ KAEK 2015/128). Tam protezleri yapilan hastalara onam formu okutulup çalışmamız hakkında açıklamalar, sözlü olarak yapıldıktan sonra imzaları alındı.

Çalışmaya 18 yaşından büyük, okuma yazması olan yazılı evrakları değerlendirebilen, fiziksel ve psikolojik sorunu olmayan, doğal dişsiz bireyler dahil edildi. Radyolojik ve klinik muayeneleri yapıldı. Katılımcıların demografik bilgileri kaydedildi.

Katılımcıların Protetik Diş Tedavisi Anabilim daIında tam protezleri yapıldı. Tam protezlerin yapımında ilk olarak hydrocolloid ölçü materyali (Kromopan lascod, LASCOD SpA, Firenze, İtalya) ile anatomik ölçüler alındı. Elde edilen ilk modellere soğuk akrilikten kişisel ölçü kaşıkları hazırlandı. Hazırlanan kaşıkların ağız içi uyumları kontrol edildikten sonra stenç (Kerr, Kerr SA Bioggio, Switzerland) ile herbst testleri yapıldı ve kenarları şekillendirildi. Fonksiyonel ölçü için hazırlanan kaşıklarda basınç gelmesi istenmeyen bölgelere delikler hazırlanıp çinko oksit öjenol ölçü (Cavex Outline, Cavex Holland BV) kullanılarak fonksiyonel ölçüler alındı. Fonksiyonel ölçülerden elde edilen modellerde kaide ve mum duvar hazırlanarak dikey boyut belirlendi. Belirlenen dikey boyuta göre diş dizimleri gerçekleştirilip hasta ağzında prova ile değerlendirildikten sonra protezler bitirildi. Protezlerin tesviye ve ağız içi uyulmamaları yapıldıktan sonra cila işlemi gerçekleştirilip hastaya teslim edildi. Hastalar 24 saat, 1 hafta, 1 ay ve 3 ay sonra kontrollere çağırılarak protez uyumlarına bakıldı.

\section{Anket Uygulamaları}

1990 yllında geliştirilen GOHAI, diş hekimliği tedavilerin etkinliğinin değerlendirilmesinde kullanılan, hastanın bildirdiği ağız sağlığı ile ilgili problemleri ve ağız sağlı̆ından kaynaklı psiko-sosyal etkileri değerlendirmeyi sağlayan bir indekstir. GOHAI anketteki 12 maddeden oluşur. Maddeler kendi içinde 5 cevap içerir ( 0 =hayır, 1 =bazen, $2=$ sıkııkla, $3=$ çok sık, 4=her zaman). Cevaplar Likert tipi ölçümle hesaplandı. 12 maddenin sonuçları toplandığında 0-48 arasında skorlar elde edildi. Toplam değerler yükseldikçe, yaşam kalitesinin düştüğü belirtildi. ${ }^{13}$ GOHAI Türkçe indeksi orijinal dili İngilizce'den Türkçe'ye çevirileri yapılmış ve güvenliği ve geçerliliği ispatlanmış bir indekstir. ${ }^{14}$ Çalışmamızda kullanılan diğer bir indeks olan OHIP 1994 yilında Slade ve Spencer ${ }^{15}$ adlı araştırmacılar tarafından geliştirildi. Hastalarda protezleri için görülen memnuniyetsizliğinin hastanın yaşam kalitesi ve mem- 
nuniyeti ile ilişkili olduğu bildirildi. ${ }^{16}$ OHIP anketi yaşam kalitesini değerlendirmede kullanılmaktadır. Slade ${ }^{17} 49$ soruluk OHIP formunu 14 soruya indirip olumlu sonuçlar veren indeks kullandı. OHIP anketinde 14 maddeye verilen cevaplar GOHAI anketindeki gibi derecelendirildi. Değerlendirme için katılımcıların her bir maddeye verdiği yanıtlar toplanarak toplam skor bulundu. OHIP-14 ölçeği Türkçe'ye üç uzman klinisyen tarafından çevrilmiş ve güvenilirliği kabullenilmiş bir yaşam kalitesi indeksidir. ${ }^{18}$

Araştırmada çiğneme testi ile beraber uygulanan son indeks OIDP, etkinin sıklığını kaydeden bir ölçümdür. ${ }^{19}$ OIDP anketi yemek yeme, konuşma, protezlerin temizlenmesi, uyuma, gülümseme, çalışma ve sosyal hayat olmak üzere günlük yaşamı etkileyen 8 maddeyi içermektedir. Her madde derecelendirmelerine göre 5 farklı değer üzerinden değerlendirildi. ${ }^{20}$ İki uzmanın konsensusu ile çevirisi yapılmış olan OIDP anketi çalışmada kullanıldı. ${ }^{7}$

Katılımcılara çiğneme testi ile beraber her seans yaşam kaliteleri ile ilgili veri sağlanabilmesi için GOHAI, OHIP ve OIDP anketleri aynı kişi tarafından hastaların kendilerini rahat hissettikleri ortamda uygulandı.

\section{Çift Renkli Sakız Çiğneme}

Sarı ve yeşil renkli ('Vivident Xylit Storming Two'- Limonata\&Kavun Perfetti Van Melle Gıda San. ve Tic. A.Ş. İstanbul/Türkiye) olan şekersiz sakız kullanıldı. Katılımcılara tam protezlerinin teslim seanslarında, ilk 24 saatlik, 1. hafta, 1. ay ve 3. ay kontrolünde olmak üzere sakız örnekler çiğnetilmiştir. Her uygulamada hastalar diş hekimi koltuğunda dik bir şekilde otururken test uygulandı. Her test uygulanan seansta, birinde 20 döngü diğerinde 50 döngü olmak üzere iki ayrı örnek katılımcılara çiğnetildi. İki örnek uygulamasının arasında 1'er dakika molalar verildi. Örnekler, çiğneme işleminden sonra fotoğrafları çekilerek görsel olarak değerlendirildi. Schimmel ve ark.'nın ${ }^{11}$ belirlediği subjektif değerlendirme skalasına göre örnekler derecelendirildi.

İstatiksel analiz SPSS programında Repeated Measure Anova ve Bonferroni testleri ile değerlendirilmiştir. Çiğneme testi için Ki-Kare testi kullanılmıştır.

\section{BULGULAR}

61,54 yaş ortalamalı 42 hastanın \%59'u kadın, $\% 41 ' i$ erkektir. (Şekil 1) \%26'sının ilk tam protezidir. \%69 ilkokul mezunu, \%22 ortaokul mezunu, \%7'si lise mezunu, \%2'si üniversite mezunudur. (Şekil 2) \%98'nin geliri asgari ücret seviyesindedir. \%74'ünde sistemik rahatsızlığı olmadığı hasta tarafından belirtilmiştir. \%83'ü sadece ağrısı olunca diş hekimine gitmektedir.

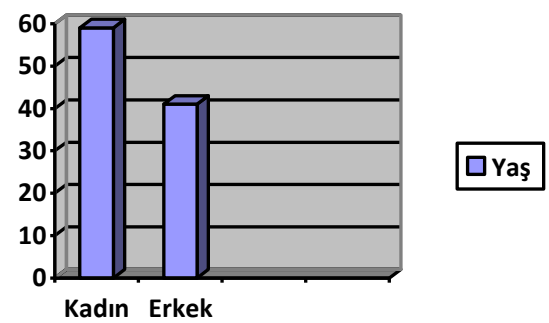

Şekil 1. Kadınların yaş ortalaması erkeklerden daha yüksek

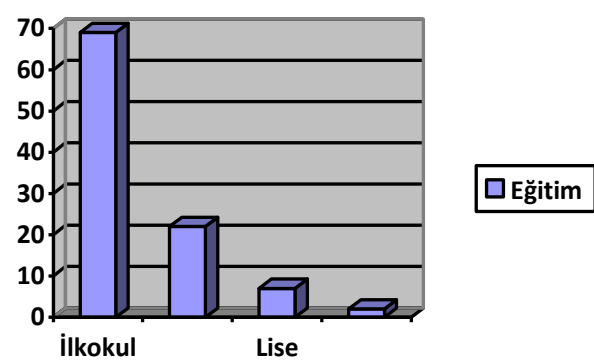

Şekil 2. Çalışmaya katılanların $\% 69$ 'u ilkokul mezuniyken $\% 2$ 'si üniversite mezunu

GOHAI değerlendirmesinde hastaların ilk taktıkları, 1. gün, 1. hafta, 1. ay ve 3. ay arası da anlamlı fark olduğu belirlenmiştir. 1 . ay ve 3 . ay arasında ise anlamlı fark olmadığı gözlenmiştir. (GOHAI $p=0.000)$

Hastaların OHIP değerlendirmelerinde protezlerin ilk takıldığı gün, 1. gün, 1. hafta, 1 . ay ve 3 . ay değerlendirilmeleri incelendiğinde aralarında anlamlı fark olduğu belirlenmiştir (OHIP $p=0.002)$. Hastaların 3. ay sonunda hayat kalitelerini arttırdığını söyleyebiliriz.

OIDP değerlendirmesinde de hastaların beş ayrı ölçümleri arasında anlamlı fark olduğu belirlenmiştir $(p=0.000)$. Hastaların değerlendirmelerinde 1 . ve 3. ay sonuçlarında anlamlı fark olmadığı belirlenmiştir.

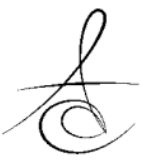


Atatürk Üniv. Diş Hek. Fak. Derg.

J Dent Fac Atatürk Uni

Cilt:28, Sayı:4, Yıl: 2018, Sayfa, 504- 510
KOÇAK BÜYÜKDERE,

DEĞİRMENCİ, ODABAŞI ÖZGÜR
Çiğneme etkinliği karşılaştırıldığında hastaların ilk gün ve 24 saat sonraki arasında anlamlı bir fark yoktur. 1 hafta, 1 ay ve 3 ay arasında anlamlı fark vardır. Çiğneme siklusları arasında anlamlı fark yoktur.

\section{TARTIŞMA}

Tam protezlerin amacı hastaların kaybettikleri fonksiyon ve estetiği hastaya kazandırmaktır. Hastaların protezlere alışmaları ve memnuniyetleri kişiden kişiye farklılık gösterir. ${ }^{21}$ Çalışmamızda tam dişsiz bireylerde rutin uygulanan konvansiyonel tam protezler yapıldı. Protezlere alışma dönemlerinde çiğneme etkinliğinin yaşam kalitesini nasıl etkilediği değerlendirildi.

Tam protezlere alışma sürecinde tam protez yapım teknikleri ve hastaların sistemik durumları uzun süredir araştırılmaktadır. ${ }^{22}$

Yapılan çalışmada hastaların protezlere adaptasyonunu etkileyen faktörleri değerlendirmiş ve erkek hastaların kadınlara göre protezlere daha kolay uyum sağladıklarını, hasta yaşının ise adaptasyon ile ilişkili olmadığını ve sistemik rahatsızlıkları bulunmayan kişilerin, bulunanlara göre daha iyi adaptasyon gösterdiklerini bildirmişlerdir. ${ }^{23}$ Yapılan başka bir çalışmada hasta beklentisi ile protez memnuniyetinin cinsiyet ile ilgisi değerlendirildiğinde, kadınlarda erkeklere göre daha yüksek estetik beklenti görüldüğü belirtilmiş. ${ }^{24}$

Kadın hastalarda, menopoz döneminde fiziksel ve duygusal değişikliklerden dolayı protez adaptasyonunun daha zor olabileceği belirtilmiştir. ${ }^{25}$ Ayrıca, ilerleyen yaş hem kadınlar hem erkekler için protezlere adaptasyonu zorlaştıran bir durum olarak belirtilmiştir. $^{26}$

Çalışmamızda hasta memnuniyeti ile cinsiyet arasında anlamlı bir ilişki bulunmamıştır. Yaşın da protez adaptasyonu ile ilişkisi bulunmamıştır. Bunun sebebi çalışmamızın bir pilot çalışma olması ve hastaların \%74'nün ilk defa tam protez kullanmamış olmaları olabilir.

Yapılan bir çalışmada tam protezlere adaptasyonda kişisel özelliklerin önemli olduğunu belirtilmiştir. Titiz ve bencil insanların genellikle protezleri ile memnun olmadıklarını bildirilmiştir. ${ }^{27}$ Kolay sinirlenen kişiler sakin bireylere göre protezlerinden memnun olma oranının daha düşük olduğunu belirten çalışmalar vardır. ${ }^{28}$

Daha önceden protez kullanan hastaların yaklaşık \%60'ı yeni protezlerin yapımından 1 hafta sonra etkili bir şekilde yeme ve konuşma fonksiyonlarını gerçekleştirdiği bildirilmiştir. Diğer \%33'ü yeterli fonksiyona 1-6 ay arası sürede ulaşabilmişlerdir. Protezlerine iyi adaptasyon gösteren hastaların \%90'nının 5 yıldan uzun süre protez kullandığı ve protezlerin sınırlamalarını bildiklerini bildirmişlerdir. ${ }^{29}$

Çalışmamızda hastaların adaptasyonunun 1 ay içinde arttığı belirlendi. Bu süre bazı hastalarda daha az bazılarında fazla olması eski protez kullanıp kullanmamaları veya kişisel özellikleri ile değişken olduğu söylenebilir.

Hastaların yeni protezlerine alışma süreci de protezin başarısı ile beraber yaşam kalitelerini de etkiler. Yeni tam protezlere alışma döneminde ki hastaların memnuniyetini değerlendirilen çalışmada 3 ve 6 aylık değerlendirme döneminde çiğneme etkinliği açısından anlamlı bir fark görülmediğini bildirmişlerdir. ${ }^{5}$ Bu çalışmada da en kritik dönem olarak belirlenen 3 aylık dönemi değerlendirdik.

Yaşam kalitesinin değerlendirilmesi, klinik uygulamalarda önemli bir etkiye sahiptir. ${ }^{6-8,30}$ OHIP anketinin amacı, ağız sağlığı durumunun sosyal açıdan önemini değerlendirmeyi amaçlar. Ayrıca yapılan çalışmalarda diş kayıpları ile beraber OHIP skorlarının etkilendiği bildirilmiştir. ${ }^{18,}{ }^{31}$ GOHAI anketinin sağlığa bağlı yaşam kalitesini ölçmede gereken kriterleri içeren kişisel ağız sağlığı değerlendirmede en iyi ölçü olduğu belirtilmiştir. $^{30}$ Ağız sağığının davranışsal önemini değerlendiren OIDP birçok ülkede uygulanan bir indekstir. ${ }^{32,33}$

Çalışmamızda hastaların yeni protezlerine alışma döneminde yaşadıkları adaptasyon sürecinin hayat kalitesine etkisini belirlemek için her seansta katılımcılara OHIP, GOHAI ve OIDP anketlerini uyguladık. OHIP, GOHAI ve OIDP, literatürde sıklıkla tercih edilen yaşam kalitesini değerlendirmede önemli veri sağlayan indekslerdir. Çalışmamızda bu indeksleri kullanarak tam protezlere alışma döneminin hastanın çiğneme etkinliği ile beraber yaşam kalitesini nasıl etkilediğini karşılaştırmalı olarak değerlendirdik.

Nicolas ve ark.larnın ${ }^{34} 143$ hastada yaptığı bir çalışmada yeni protezleri yapılan hastaya tedavinin başında, 3 ay sonra ve 6 ay sonra olmak üzere GOHAI indeksi uygulanmış. GOHAI kategorilerindeki skorlarda zaman geçtikçe anlamlı derecede gelişme görüldüğü bildirilmiş.

Literatürde GOHAI ve OHIP-14 indekslerini ileri yaşı bireylerde karşılaştıran çalışmalar vardır. ${ }^{30,35-37}$ 
Atatürk Üniv. Diş Hek. Fak. Derg.

J Dent Fac Atatürk Uni

Cilt:28, Sayı:4, Yıl: 2018, Sayfa, 504- 510

OIDP ve OHIP-14 indekslerini karşılaştıran çalışmalar da bulunmaktadır. İspanya da yapılan bir çalışmada iki indeks karşılaştırılmış. Tutarlılık değerleri (Cronbach's alpha) OHIP-14 için 0.89 ve OIDP için 0.74 bulunmuş. İki indeksin birbirleri ile tutarlı sonuçlar verdiğini bildirimişler. ${ }^{33}$

Karşılaştırmalı çalışmalarda birbirleri ile tutarlı sonuçlar veren bu üç farklı indeksi yaşam kalitesi değerlendirmesinde çalışmamızda değerlendirdik.

OHIP değerlendirmelerinde protezlerin ilk takıldığı gün, birinci gün, bir hafta, bir ay ve 3 ay değerlendirilmeleri incelendiğinde aralarında anlamlı fark olduğu belirlendi. Hastaların proteze adaptasyonlarının 3 ay içinde olduğunu ve alışma ile beraber hayat kalitesinin arttı.

GOHAI değerlendirmesinde hastaların ilk taktıkları, birinci gün, birinci hafta, birinci ay ve üçüncü ay arası da anlamlı fark olduğu belirlenmiştir. 1. ay ve 3. ay arasında ise anlamlı fark olmadığı gözlenmiştir. Hastaların protezlere adaptasyonları ve fiziksel uyumları 1 ay içinde gerçekleşti.

OIDP değerlendirmesinde de hastaların beş ayrı ölçümleri arasında anlamlı fark olduğu belirlendi. Hastaların değerlendirmelerinde 1 . ve 3 . ay sonuçlarında anlamlı fark olmadığı belirlendi.

Literatürde, çeşitli çiğneme testleri araştırmacılar tarafından kullanılmıştır. Elek yöntemi, yutma eşiği testi, bilgisayar destekli görüntü analizi, ezme yeteneği testi kullanılan yöntemlerdir. Elek yönteminde, çeşitli sayılarda çiğneme döngülerinden sonra test örneği toplanarak çeşitli büyüklükteki eleklerden geçirilir ve elek üzerinde kalan örneklerin ağırlığı hesaplanır. ${ }^{38}$

Yutma eşiği testinde ise katılımcılar test örneğini yutacak duruma gelene kadar çiğnerler ve örnek bir elekten geçirilir, elenmiş yiyecek hacmi ile toplam hacim arasındaki oran çiğneme performansını verir. ${ }^{9,10}$ Ezme yeteneği testi, elek metoduna benzemektedir. Katılımcılar yapay test materyalini çiğnerler ve belirlenen elek üzerinde kalan ezilmiş test materyalinin dağılım büyüklüğü bilgisayar destekli görüntü analizi ile değerlendirilir. ${ }^{6}$ Sakız çiğneme testi pratik, vakit kazandıran gibi avantajlara sahip olması ile beraber elastik yapısı ile maksimum çiğneme kuvvetine imkan tanır. Ayrıca, partiküllere ayrılmadığı için kayıp örnek olmaz ve bu değerlendirmeyi etkilemez. ${ }^{39}$ Çift renkli sakız çiğneme hassas ve güvenli bir değerlendirme sağlar. ${ }^{11,12}$
KOÇAK BÜYÜKDERE,

DEĞİRMENCİ, ODABAŞI ÖZGÜR

Bundan dolayı çalışmamızda da çift renkli sakız çiğneme testi uygulandı. Çiğneme testinin renk karışımı değerlendirilmesi görsel olarak yapıldı.

Literatürde de görsel değerlendirmenin bilgisayar analizi ile yapılan değerlendirmeye benzer doğruluk sağladığını belirtilmektedir. ${ }^{12}$ Bununla beraber, bilgisayar analizinin görsel değerlendirmeye kıyasla daha iyi sonuç verdiğini savunan görüşler de vardır. ${ }^{11}$

Cunha ve ark. $^{2}$ bazikfuksin içeren tanecikleri kullanarak yaptıkları çiğneme etkinliği çalışmasında çiğneme döngülerinin çiğneme performansı sonuçları üzerinde etkili olduğunu 40 döngüden sonra daha iyi parçalanma görüldüğünü bildirmişlerdir. Endo ve ark. ${ }^{40}$ yaptıkları çalışmada katılımcılara çift renkli sakız örneklerini 5, 10, 20, 30 ve 50 döngü olacak şekilde çiğneme işlemi yaptırmışlardır. Çalışmada verileri değerlendirdiklerinde 20 veya 30 çiğneme döngüsünün değerlendirmede uygun olduğunu bildirmişlerdir.

Çalışmamızda bu veriler doğrultusunda 20 ve 50 çiğneme döngüleri tercih edildi. Her döngüde de ilk ölçüm ve ikinci ölçüm arasında anlamlı fark bulunmadı. Bunu da protezlerin ilk takıldığında vuruk olma olasılığının daha yüksek olduğu ve ağrı oluşacağı için hastaların etkin çiğneme yapamayacaklarından olduğunu düşünüyoruz. Proteze adaptasyonun artması fonksiyon özelliklerinin artması ve protezlere kabullenilmesinden dolayı çiğneme etkinliğinin arttığını düşünüyoruz.

\section{SONUÇ}

Bu pilot çalışmada elde ettiğimiz sonuçlar

1- Hastaların gelirleri ve eğitim durumları konvansiyonel tam protez seçimini etkiler.

2- Hastaların fiziksel olarak tam proteze adaptasyonları bir ay içinde çoğunlukla gerçekleşmektedir. Bir ay ile üç ay arasında anlamlı farklılık yoktur.

3- Hastaların protezlerine psikolojik adaptasyonu üç aya kadar sürmektedir.

Hastaların çiğneme kabiliyetleri ilk 24 saat içinde vuruktan kaynaklı ağrılardan dolayı yeterli olmadığını ama bir hafta içinde 3 aya kadar anlamlı olarak artma olduğunu söyleyebiliriz.

Çıkar/ilişki durumu: 'Bu makalede bahsi geçen konu ile ilgili herhangi bir ilişki, bağlantısı veya parasal çıkar durumu söz konusu değildir'

AYşe KOÇAK BÜYÜKDERE: ORCID ID: 0000-0003-1942$456 X$

Kübra DEĞİRMENCİ: ORCID ID: 0000-0001-6429-4923 
Atatürk Üniv. Diş Hek. Fak. Derg.

J Dent Fac Atatürk Uni

Cilt:28, Sayı:4, Yıl: 2018, Sayfa, 504- 510
KOÇAK BÜYÜKDERE, DEĞİRMENCİ, ODABAŞI ÖZGÜR

\section{KAYNAKLAR}

1. Özdemir Ö, Akören C. Tam protezlerde çiğneme etkinliği Atatürk Üniv Diş Hek Fak Derg 2010; Supp.3: 60-9.

2. Cunha $T R$, DellaVecchia $M P$, Regis RR, Ribeiro $A B$, Muglia VA, Mestriner W Jr, de Souza RFA. Randomised trial on simplified and conventional methods for complete denture fabrication masticatory performance and ability. J Dent 2013; 41:133-42.

3. Çalıkkocaoğlu S. Dişsiz Hastaların Protetik Tedavisi 5. baskı 2010 İstanbul: 96

4. Trulsson M. Sensory-motor function of human periodontal mechanoreceptors. J Oral Rehabil 2006;33:262-73.

5. Farias-Neto A, Carreiro Ada F. Changes in patient satisfaction and masticatory efficiency during adaptation to new dentures. Compend Contin Educ Dent 2015;36:174-7.

6. Sato Y, Kaiba Y, Yamaga E, Minakuchi S. Reliability and validity of a Japanese version of the Oral Health Impact Profile for edentulous subjects. Gerodontology 2012;29:1033-7.

7. Peker I, Alkurt MT. Oral impacts on daily performance in Turkish adults attending a dental school. JCDP. 2014;15: 92-98.

8. Yıldız S, Işık G Geriatrik Hastalarda Protezlerin Ağız Sağlığı ve Yaşam Kalitesi Üzerine Etkisi. İst Ünv. Dişhek Fak Derg. 2012;46:11-6.

9. Schimmel M, Leemann B, Herrmann FR, Kiliaridis $S$, SchniderA, Muller F. Masticatory function and bite force in stroke patients. J Dent Res 2011;90: $230-4$.

10. van den Braber W, van der Glas $H$, van der Bilt $A$, BosmanF. Masticatory function in retrognathic patients before and after mandibular advancement surgery. J Oral Maxillofac Surg 2004;62:549-54.

11. Schimmel M, Christou P, Herrmann F, Muller F. A two-colour chewing gum test for masticatory efficiency: development of different assessment methods. J Oral Rehabil 2007;34:671-8.

12. Prinz JF. Quantitative evaluation of the effect of bolus size and number of chewing strokes on theintro-oral mixing of a two colour chewing gum. J Oral Rehabil 1999;26:243-7.

13. Tubert-Jeannin S, Riordan PJ, Morel-Papernot A, Porcheray S, Saby-Collet S. Validation of an oral health quality of life index (GOHAI) in France.
Community Dent Oral Epidemiol 2003;31:275-84.

14. Ergül S, Akar GC. Reliability and validity of the Geriatric Oral Health Assessment Index in Turkey. J Gerontol Nurs 2008;34:33-9.

15. Slade GD, Spencer AJ. Development andevaluation of the Oral Health Impact Profile. Community Dent Health 1994;11:3-11.

16. Baran I, Nalcaci R. Self-reported problems before and after prosthodontic treatments according to newly created Turkish version of oral health impact profile. Arch Gerodont. Geriat 2011;53:99-105.

17. Slade GD. Derivation and validation of a short-form oral health impact profile. J Community Dent Oral Epidemiol 1997;25:284-90.

18. Başol ME, Karaağaçlıŏlu L,Yılmaz B. Türkçe Ağız Sağlığı Etki Ölçeğinin Geliştirilmesi-OHIP-14-TR. Türkiye Klinikleri J Dental Sci 2014;20:85-92.

19. Allen PF. Assessment of oral health related quality of life. Health Qual Life Outcomes 2003;40:1-8.

20. Mumcu G, Hayran O, Ozalp DO, Inanc N, Yavuz $\mathrm{S}$, Ergun $\mathrm{T}$, Direskeneli $\mathrm{H}$ The assessment of oral health-related quality of life by factor analysis in patients with Behcet's disease and recurrent aphthousstomatitis.J Oral PatholMed 2007;36:14752.

21. Knezovic D, C`elebic A. Treatment outcomes with removable partial dentures: A comparison between patient and prosthodontist assessments. Int ] Prosthodont 2001;14: 423-6.

22. Kalk W. Baat C, Kaandorp A J. Comparison of patients' views and dentists' evaluation 5 years after complete denture treatment. Comm Dent Oral Epid 1991;19:213-6.

23. Panek H, Krawczykowska H, Dobosz A, Napadłek P, Panek BA, Sosna-Gramza M. Follow-up visits as a measure of adaptation process to removable prostheses. Gerodontology 2006;23:87-92.

24. Santos BFO, Santos MBF, Santos JFF, Marchini L. Patients' Evaluations of Complete Denture Therapy and Their Association with Related Variables: A Pilot Study. J Prosthodont 2015:24;351-7.

25. Winkler S. Psychologicalaspects of treating complete denture patients: their relation to prosthodontic success. J Geriatr Psychiatry Neurol 1989;2:48-51.

26. Ettinger R. Some observations on the diagnosis and treatment of complete denture problems. Aust Dent J 1978;23:457-64.

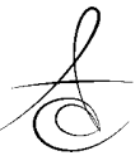


Atatürk Üniv. Diş Hek. Fak. Derg.

] Dent Fac Atatürk Uni

Cilt:28, Sayı:4, Yıl: 2018, Sayfa, 504- 510

27. Reeve P, Watson C, Stafford G. Theuse of Cattell'spersonalityprofile in patientswhohave had preprostheticsurgery, Journal Dent 1982;10:12130.

28. Guckes AD, Smith DE, Swoope CC. Counseling and related factors influencing satisfaction with dentures. J Prosthet Dent 1978;39:259-267.

29. Bergman B, Carlsson GE. Review of 54 complete denture wearers. Patients' opinions 1 year after treatment. Acta Odontol Scand 1972;30:399-414.

30. Locker D, Matear D, Stephens M, Lawrence $\mathrm{H}$, Payne B. Comparison of the GOHAI and OHIP 14 as measures of the oral health-related quality of life of the elderly. Community Dent Oral Epidemiol 2001;29:373-81.

31. Robinson PG, Gibson B, Khan FA, Bimbaum W. Comparison of OHIP 14 and OIDP as interviews and questionnaires. Community Dent Health 2001; 18:144-9.

32. Dorri M, Sheiham A, Tsakos G. Validation of a Persian of the OIDP index. BMC oral Health 2007;26:2-7.

33. Nicolas E, Veyrune JL, Lassauzay CA six-month assessment of oral health-related quality of life of complete denture wearers using denture adhesive: a pilot study. J Prosthodont 2010;19:443-8.

34. 34- Hassel AJ, Steuker B, Rolko C, Keller L, Rammelsberg $\mathrm{P}$, Nitschke I: Oral health-related quality of life of elderly Germans comparison of GOHAI and OHIP-14. Community Dent Health 2010;7:242-247.

35. Kebe K, Hazeyama T, Enoki K, Murai S, Okada T, Kagawa R, Matsuda K, //Maeda Y: Comparison of GOHAI and OHIP-14 measures in relation to objective values of oral function in elderly Japanese. Community Dent Oral Epidemiol 2012; 40:406-14.

36. Osta N, Tubert-Jeannin S, Hennequin M, Naaman NBA, Osta L, Geahchan N: Comparison of the OHIP-14 and GOHAI as measures of oral health among elderly in Lebanon. Health Qual Life Outcomes 2012;131:1-10.

37. Montero J, López JF, Vicente M-P, Galindo M-P, Albaladejo A, Bravo M. Comparative validity of the OIDP and OHIP-14 in describing the impact of oral health on quality of life in a cross-sectional study performed in Spanish adults. Med Oral Patol Oral Cir Bucal 2011; 16: 816-21.
KOÇAK BÜYÜKDERE, DEĞİRMENCİ, ODABAŞI ÖZGÜR

38. Ohara A, Tsukiyama Y, Ogawa T, Koyano K. A simplifiedsieve method for determining masticatory performance using hydrocolloid material. J Oral Rehabil 2003;30:927-35.

39. Anastassiadou V, Heath MR. The development of a simple objective test of mastication suitable for older people, using chewinggums. Gerodontology 2001;18:79-86.

40. Endo T, Komatsuzaki A, Kurokawa $H$, Tanaka $\mathrm{S}$, Kobayashi $\mathrm{Y}$, Kojima $\mathrm{K}$ two-colored chewing gum test for assessing masticatory performance: a preliminary study. Odontology. 2014;102:68-75.

\section{Yazışma Adresi}

Dr. Öğretim Üyesi Ayşe KOÇAK BÜYÜKDERE

Kocaeli Üniversitesi

Diş Hekimliği Fakültesi

Yuvacık Yerkleşkesi Paşadağ Mah.

Akçakesme Sok. No:5

41190 Yuvacık - Başiskele Kocaeli Türkiye

Telefon: + 905323165759

Faks: + 902623442109

Email: a.buyukdere@yahoo.com 